\title{
The impact of the COVID-19 pandemic on the echocardiographic services and training in Poland
}

\author{
Writing Committee: Piotr Lipiec ${ }^{1}$, Andrzej Gackowski², Jarosław D Kasprzak33, Katarzyna Mizia-Stec ${ }^{4}$, \\ Magdalena Lipczyńska5 ${ }^{5}$ Piotr Szymański ${ }^{6}$ \\ Contributors: Wojciech Braksator ${ }^{7}$, Maria Dudziak, Dominika Filipiak-Strzecka³, Zbigniew Gąsior ${ }^{9}$, Piotr Hoffman ${ }^{5}$, \\ Anna Klisiewicz ${ }^{5}$, Wojciech Kosmala10, Małgorzata Knapp ${ }^{11}$, Marcin Kurzyna ${ }^{12}$, Dorota Kustrzycka-Kratochwil ${ }^{13}$, \\ Zofia Oko-Sarnowska ${ }^{14}$, Agnieszka Pawlak ${ }^{15}$, Wojciech Płazak ${ }^{16}$, Edyta Płońska-Gościniak17, Piotr Pruszczyk ${ }^{18}$, \\ Piotr Scisło ${ }^{19}$, Grzegorz Skonieczny ${ }^{20}$, Bożena Sobkowiczz" ${ }^{11}$ Danuta Soryszz' ${ }^{21}$ Lidia Tomkiewicz-Pająk22, \\ Olga Trojnarska ${ }^{14}$, Paulina Wejner-Mik ${ }^{3}$, Andrzej Wysokiński23, Beata Zaborska ${ }^{24}$
}

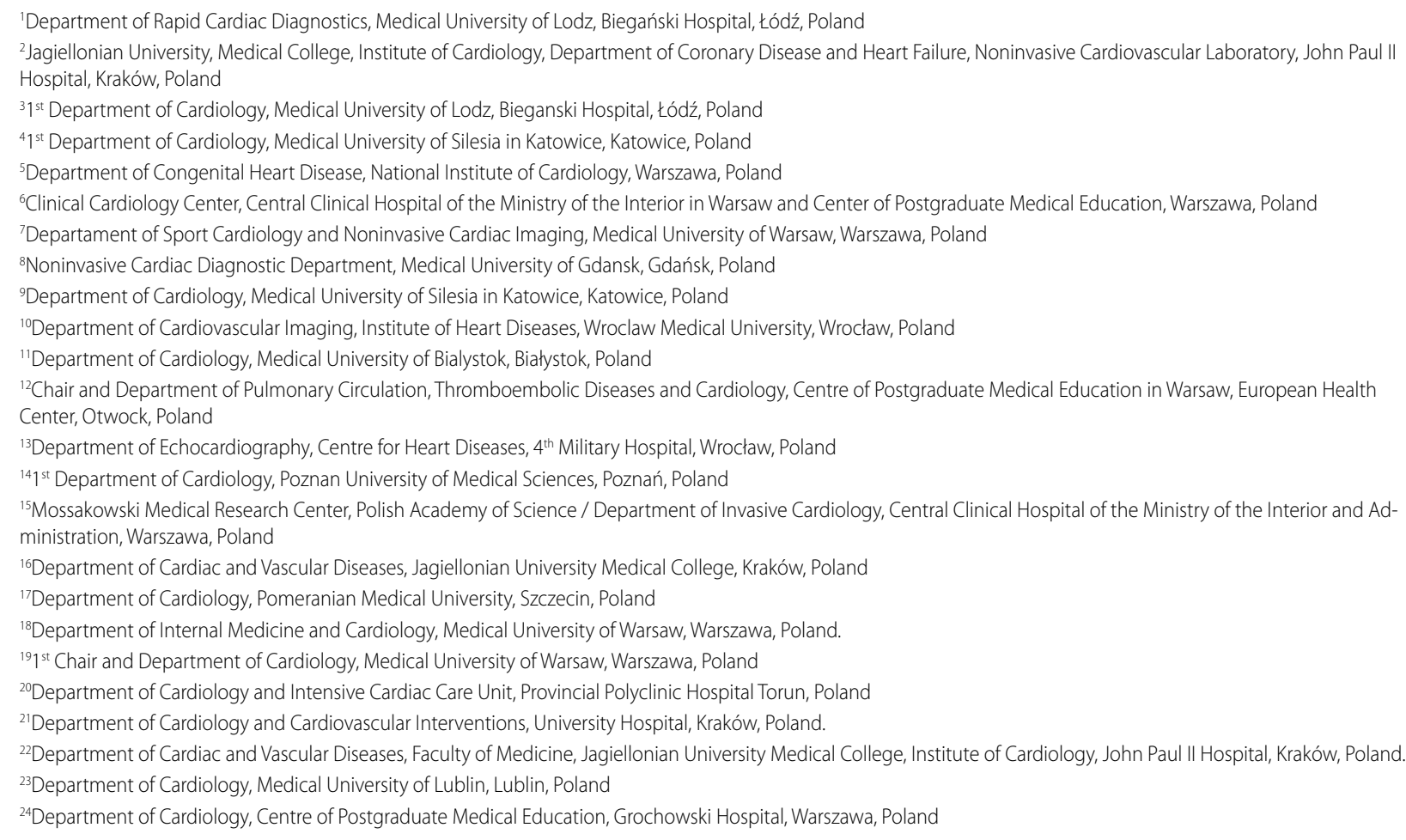

Correspondence to: Prof. Piotr Lipiec, MD PhD, Department of Rapid Cardiac Diagnostics, Medical University of Lodz, Kniaziewicza $1 / 5$ 91-347 Łódź, Poland, phone: +48 4225162 16, e-mail: lipiec@ptkardio.pl Copyright by the Author(s), 2021

Kardiol Pol. 2021;

79 (10): 1136-1139;

DOl: 10.33963/KP.a2021.0102

Received: August 4, 2021

Revision accepted: September 1, 2021

Published online: September 1, 2021

\section{INTRODUCTION}

COVID-19 pandemic has dramatically influenced the healthcare systems around the world, including cardiology services. When infections rates were peaking, a significant part of available resources was repurposed towards fighting the pandemic. Moreover, in 2020 cardiology practitioners were advised by numerous guidelines and official recommendations to defer scheduled elective procedures, especially those associated with an increased risk of severe acute respiratory syndrome coronavirus 2 (SARSCoV-2) transmission, such as transesophageal echocardiography (TEE) [1]. On top of that, patients' fear of infection and the desire not to overburden the healthcare systems kept them from seeking medical care in case of symptoms unrelated to COVID [1].

Therefore, it comes as no surprise, that data published so far indicates a significant and abrupt reduction in cardiac care services in numerous countries and regions. It has been reported that the cumulative number of hospitalizations for acute and chronic cardiovascular conditions, as well as the number of outpatient cardiovascular visits, had substantially de- 
creased [1,2]. The latter was only partly compensated using telemedicine. There has also been a significant drop in the number of various inpatient and outpatient cardiac procedures and examinations, including echocardiography [1,2].

Importantly, the COVID-19 pandemic has affected medical education, not only for undergraduates but also for residents and post-graduate trainees [1]. The reduction in the number of cases and supervised procedures, as well as canceled educational activities, a shift of educational curricula towards online didactics, postponed examinations and altered rotations have already been documented in some specializations $[2,3]$.

However, details of the pandemic's impact on echocardiographic laboratories are still unclear. Furthermore, there is no data on the current state of post-graduate hands-on training in echocardiography. In order to shed more light on this issue and to identify the most important implications and possible obstacles for restoring the pre-pandemic activity of echocardiographic services and training, the Working Group on Echocardiography of the Polish Cardiac Society performed a national survey to evaluate echocardiographic practices and postgraduate training in echocardiography in Poland during the pandemic.

\section{METHODS}

This retrospective survey was based on questionnaires filled out by 23 participating Polish echocardiographic centers. We attempted to include a large number of laboratories to cover all regions of the country in order to account for practice variations related to differences in infection rates and local regulations regarding healthcare. To encourage participation, we reached out via e-mails and phone calls to experts working in echocardiographic laboratories with active post-graduate education programs identified in the database of the Working Group on Echocardiography of the Polish Cardiac Society. Each center was asked to fill out a questionnaire regarding their practices in the 9-month period representative of the pre-pandemic activity (April-December 2019) and in the 9-month pandemic period (April-December 2020). Importantly, because during the pandemic there were phases with various infection rates and different degrees of the potential impact on the echocardiographic practices, we concentrated not only on the average monthly test volume but also on the minimal monthly test volume in the analyzed periods.

\section{Statistical analysis}

Continuous variables were initially tested for normality of data distribution by the Kolmogorov-Smirnow test. Normally distributed variables are expressed as mean (standard deviation [SD]). Non-normally distributed variables are presented as median (interquartile range [IQR]). Categorical variables are presented as percentages (\%). Paired samples t-test was used to compare the examination of volume between the pre-pandemic and the pandemic periods for data with normal distribution whereas, for non-normally distributed data, the Wilcoxon test was used (MedCalc Software, Frank Schoonjans, Belgium). The differences in the examination volume were considered statistically significant at $P<0.05$.

\section{RESULTS AND DISCUSSION}

The mean and minimal monthly test volumes in the participating centers in the pre-pandemic and pandemic period are presented in Table 1. During the pandemic, 9 centers (39.1\%) were partially transformed into COVID-19 facilities, whereas 3 others (13.0\%) were transformed into centers only for COVID-19 patients. Transthoracic echocardiography (TTE) and TEE were performed in patients with COVID-19 in 18 (78.2\%) and 9 (39.1\%) centers, respectively (the median/mean of cumulative numbers of tests were 21 (20-100) and 5 (6), respectively). Stress echocardiography was not performed in patients with COVID-19.

Three labs (13.0\%) underwent temporary suspension of all their activities due to either quarantine or diagnosis of COVID-19 in all staff members. Three sites (13.0\%) suspended temporarily only their out-patients services due to local regulations. In 21 (91.3\%) centers at least one staff member (on average 3 [2]) was quarantined, whereas in 18 (78.2\%) labs there were confirmed cases of COVID-19 among the personnel (on average 2 [1]). Seven (30.4\%) sites reported temporary shortages of personal protective equipment, which on average lasted 70 (83) days.

A negative COVID-19 test was required before TTE, TEE, and stress echocardiography in 9 (39.1\%), 17 (73.9\%), and $10(43.5 \%)$ centers, respectively. Body temperature check was performed before TTE, TEE, and stress echocardiography in 18 (78.3\%), 17 (73.9\%), and 14 (60.9\%) labs, respectively.

The indications for TTE, TEE, and stress echocardiography were limited in 6 (26.1\%), 12 (52.1\%), and 10 (43.5\%) sites, respectively. Additional disinfection procedures visibly reduced temporal availability of resources in 12 (52.2\%) labs by 21 (11)\% on average. The examination protocols for TTE, TEE, and stress echocardiography were shortened in $5(21.7 \%), 5(21.7 \%)$, and 1 (4.3\%) centers, respectively.

The scheduled examinations were delayed or canceled in $12(52.2 \%)$ and 6 (26.1\%) labs, respectively. Similarly, waiting times for elective procedures following echocardiography - cardiac surgery, percutaneous coronary intervention, structural transcatheter procedure, and electrotherapy - were prolonged in 15 (65.2\%), 12 (52.2\%), 13 (56.5\%), and 12 (52.2\%) centers, respectively. Furthermore, there was no possibility of scheduling elective cardiac surgeries, percutaneous coronary interventions, structural transcatheter procedures, or electrotherapy after echocardiographic examination in 3 (13.0\%), 1 (4.3\%), 2 (8.7\%), and 1 (4.3\%) sites, respectively.

Importantly, the pandemic significantly affected post-graduate hands-on training in echocardiography. The overwhelming majority (90.9\%) of centers, which had been actively teaching before the pandemic, reported that 
Table 1. Monthly examination volume in the pre-pandemic period (April-December 2019) and during the COVID-19 pandemic (April-December 2020) in the Polish echocardiographic laboratories

\begin{tabular}{|c|c|c|c|c|}
\hline & $\begin{array}{l}\text { Pre-pandemic period, } \\
\text { mean (SD) or median } \\
\text { (IQR) }\end{array}$ & $\begin{array}{l}\text { Pandemic period, } \\
\text { mean (SD) or median } \\
\text { (IQR) }\end{array}$ & $\begin{array}{l}\text { Mean relative change } \\
\text { in test volume }(\%)\end{array}$ & $P$-value \\
\hline \multicolumn{5}{|c|}{ In-patient services } \\
\hline \multicolumn{5}{|c|}{ Mean monthly test volume } \\
\hline TTE & $389(261)$ & $273(226)$ & -29.9 & $<0.001$ \\
\hline TEE & $37(30)$ & $21(18)$ & -45.9 & 0.004 \\
\hline TPM & $8(6)$ & $5(5)$ & -37.5 & 0.0497 \\
\hline Stress tests & $8(7)$ & $3(4)$ & -62.5 & $<0.001$ \\
\hline \multicolumn{5}{|c|}{ Minimal monthly test volume } \\
\hline TTE & $298(202)$ & 159 (147) & -46.4 & $<0.001$ \\
\hline TEE & $27(23)$ & $9(12)$ & -64.3 & $<0.001$ \\
\hline TPM & $1(0-5)$ & $0(0-1)$ & & 0.008 \\
\hline Stress tests & $4(6)$ & $1(1)$ & -75.0 & 0.02 \\
\hline \multicolumn{5}{|c|}{ Out-patient services } \\
\hline \multicolumn{5}{|c|}{ Mean monthly test volume } \\
\hline TTE & $147(127)$ & $100(91)$ & -32.0 & 0.009 \\
\hline TEE & $12(12)$ & $4(5)$ & -66.7 & 0.012 \\
\hline Stress tests & $7(5)$ & $3(3)$ & -57.1 & 0.04 \\
\hline \multicolumn{5}{|c|}{ Minimal monthly test volume } \\
\hline TTE & $61(27-200)$ & $2(0-15)$ & & $<0.001$ \\
\hline TEE & $3(2-8)$ & $0(0-0)^{\mathrm{a}}$ & & 0.004 \\
\hline Stress tests & $1(0-5)$ & $0(0-0)^{a}$ & & 0.03 \\
\hline
\end{tabular}

aOnly 2 centers maintained minimal monthly test volume higher than 0 throughout the pandemic period

Abbreviations: IQR, interquartile range; SD, standard deviation; TEE, transesophageal echocardiography; TPM, transcatheter procedure monitoring; TTE, transthoracic echocardiography

they had either no or fewer trainees involved in activities (13 [59.1\%] and 7 [31.8\%] sites, respectively). At the same time, practical workshops, which had been regularly organized or accredited by the Working Group on Echocardiography of the Polish Cardiac Society before the pandemic, were either canceled or reformatted into online webinars and lecture-based courses.

To summarize, this survey documents a dramatic reduction of echocardiographic services, especially TEE and stress echocardiography, and confirms the need to urgently restore the full capacity of echocardiographic laboratories, as recommended in our recent Expert Opinion [2]. Furthermore, our data demonstrate a long pause in hands-on post-graduate training in echocardiography, which may adversely influence the quality of cardiology services for many years to come. To avoid such detrimental effects, we recommend a prompt reactivation of full-scale post-graduate hands-on training programs in the teaching centers, as soon as pandemic-related restrictions allow. Obviously, the level of personal protection of all trainees should be identical to the protection provided for the staff members (see the aforementioned recent Expert Opinion for details). Moreover, echo laboratories and other medical services should be prepared to maintain their activities despite the possible future pandemic waves.

\section{Article information}

Conflict of interest: None declared.

Open access: This article is available in open access under Creative Common Attribution-Non-Commercial-No Derivatives 4.0 International (CC BY-NC-ND 4.0) license, allowing to download articles and share them with others as long as they credit the authors and the publisher, but without permission to change them in any way or use them commercially. For commercial use, please contact the journal office at kardiologiapolska@ptkardio.pl.

How to cite: Lipiec P, Gackowski A, Kasprzak JD, et al. The impact of the COVID-19 pandemic on the echocardiographic services and training in Poland. Kardiol Pol. 2021; 79(10): 1136-1139, doi: 10.33963/KP.a2021.0102.

\section{REFERENCES}

1. Gackowski A, Lipczyńska M, Lipiec P, et al. Review Committee, Reviewers (on behalf of the Polish Cardiac Society). Echocardiography during the coronavirus disease 2019 (COVID-19) pandemic: expert opinion of the Working Group on Echocardiography of the Polish Cardiac Society. Kardiol Pol. 2020; 78(4): 357-363, doi: 10.33963/KP.15265, indexed in Pubmed: 32241097.

2. Moroni F, Gramegna M, Ajello S, et al. Collateral damage: medical care avoidance behavior among patients with myocardial infarction during the COVID-19 pandemic. JACC Case Rep. 2020; 2(10): 1620-1624, doi: 10.1016/j.jaccas.2020.04.010, indexed in Pubmed: 32835261.

3. Bollmann A, Pellissier V, Hohenstein S, et al. Cumulative hospitalization deficit for cardiovascular disorders in Germany during the Covid-19 pandemic. Eur Heart J Qual Care Clin Outcomes. 2021; 7(4): e5-e6, doi: 10.1093/ehjqcco/qcaa071, indexed in Pubmed: 32857835. 
4. Wosik J, Clowse MEB, Overton R, et al. Impact of the COVID-19 pandemic on patterns of outpatient cardiovascular care. Am Heart J. 2021; 231: 1-5, doi: 10.1016/j.ahj.2020.10.074, indexed in Pubmed: 33137309.

5. Fersia O, Bryant S, Nicholson R, et al. The impact of the COVID-19 pandemic on cardiology services. Open Heart. 2020; 7(2): e001359, doi: 10.1136/openhrt-2020-001359, indexed in Pubmed: 32855212.

6. Einstein AJ, Shaw $L$, Hirschfeld C, et al. the, INCAPS COVID Investigators Group. International impact of COVID-19 on the diagnosis of heart disease. J Am Coll Cardiol. 2021; 77(2): 173-185, doi: 10.1016/j.jacc.2020.10.054, indexed in Pubmed: 33446311.

7. Alsoufi A, Alsuyihili A, Msherghi A, et al. Impact of the COVID-19 pandemic on medical education: medical students' knowledge, attitudes, and practices regarding electronic learning. PLoS One. 2020; 15(11): e0242905, doi: 10.1371/journal.pone.0242905, indexed in Pubmed: 33237962
8. Sneyd JR, Mathoulin SE, O'Sullivan EP, et al. Impact of the COVID-19 pandemic on anaesthesia trainees and their training. $\mathrm{Br} J$ Anaesth. 2020; 125(4): 450-455, doi: 10.1016/j.bja.2020.07.011, indexed in Pubmed: 32773215 .

9. Aziz H, James T, Remulla D, et al. Effect of COVID-19 on surgical training across the United States: a national survey of general surgery residents. J Surg Educ. 2021;78(2):431-439, doi: 10.1016/j.jsurg.2020.07.037, indexed in Pubmed: 32798154.

10. Szymański P, Gackowski A, Mizia-Stec K, et al. Echocardiography during the coronavirus disease 2019 pandemic — the impact of the vaccination program. A 2021 update of the expert opinion of the Working Group on Echocardiography of the Polish Cardiac Society. Kardiol Pol. 2021; 79(5): 595-603, doi: 10.33963/KP.15973, indexed in Pubmed: 34125943. 